\title{
Investigation of changes in the geomechanical properties of oil-contaminated sand in geotechnical construction
}

\author{
Arthur Manko ${ }^{1}$ \\ ${ }^{1}$ Moscow State University of Civil Engineering, Yaroslavskoe shosse, 26, Moscow, 129337, Russia
}

\begin{abstract}
In this article consider the a present results of the scientific work directed on learnin change of geomechanical properties of sand from pollution its of light hydrocarbon.
\end{abstract}

\section{Introduction}

Results of scientific work, which has been made in Moscow State University of Civil Engineering, on a research of change of geomechanical properties of sandy soil of the Moscow region at their pollution by light hydrocarbons, are presented in this article.

In this scientific research river sand was used. Main characteristics of river sand following [1]: specific weight of river sand $2.65 \mathrm{~g} / \mathrm{cm}^{3}$, density of dry river sand $1.5 \mathrm{~kg} / \mathrm{m}^{3}$, density in a condition of natural humidity of $1.45 \mathrm{~g} / \mathrm{cm}^{3}$.

This sand was sifted to separate various garbage from sand. Further sand on bolter has been divided into fractions according to Classification of Soil [2]. From the received fractions of sand two have been selected. Most of which often meet in the Moscow region:

- Fine sand with fraction size of grains from $0.1 \mathrm{~mm}$ up to $0.25 \mathrm{~mm}$.

- Medium sand with size of grains from $0.25 \mathrm{~mm}$ up to $0.5 \mathrm{~mm}$.

As lungs hydrocarbon took benzine (gasoline) and the diesel.

Mix of benzine (gasoline) from various producers and different brands was applied to researches. It was made to receive the benzine (gasoline) [3] average on the properties: boiling point of $33-205^{\circ} \mathrm{C}$, density is about $0.71 \mathrm{~g} / \mathrm{cm}^{3}$, freezing temperature $-72^{\circ} \mathrm{C}$.

The diesel was also used as mix from various producers of one brand. At the time of carrying out a research on sale there was only a "Summer" diesel brand with the following characteristics [4]: density is no more than $860 \mathrm{~kg} / \mathrm{m}^{3}$, flash point of $62^{\circ} \mathrm{C}$, set point: $-5^{\circ} \mathrm{C}$.

\section{Preparation for an experiment}

\subsection{Sand preparation}

Sands in a natural state have various degree of wetness, which substantially influences ability to get into the sandy massif of benzine (gasoline) and the diesel. 
According to Classification of Soils by water saturation coefficient sands happen the low-wet, the wet and water-saturated. For an experiment it was decided to use sands the low-wet and water-saturated.

The drying chamber is in vitro applied to receiving sands from a condition of natural humidity to the low-wet. According to normative documents [5-7] in a drying chamber dry sand 30 minutes at a temperature of $110 \pm 5^{\circ} \mathrm{C}$. Further the humidity coefficient is checked. If it makes from $0 \%$ to $0.5 \%$, then such sand is the low-wet. If the coefficient of humidity makes from $0.8 \%$ to $1.0 \%$, then such sands are water-saturated.

After sand drying the coefficient of water saturation of sands made $0.34 \%$. This sand for laboratory researches is conditionally accepted as the low-wet. For receiving watersaturated sands the low-wet sand after drying was moistened to a state when sand did not absorb water. After check in a drying chamber the coefficient of humidity made $0.98 \%$. Such sand for laboratory researches is conditionally accepted as water-saturated sand.

\subsection{Preparation for definition of geomechanical characteristics of sands}

Each soil has a set of physical and mechanical properties from which their unique geomechanical characteristics turn out. A basis the parameter for sands, geomechanical characteristics defining them, is indexes of deformability (compressibility) of the sandy massif. First of all these indicators need to be known for calculation of stability of the building.

One of ways of determination of deformability of sand in vitro are compression tests. It tests of a soil in the conditions of an axial compression without a possibility of side expansion. Compression tests carry out in odometers.

In this research was used the compression device model "KPr-1" with the odometer. Main principal specifications of the odometer following: a sectional area of an exemplar of $60 \mathrm{~cm}^{2}$, depth of $2.5 \mathrm{~cm}$, the squeezing pressure upon an exemplar of a soil of $0.006-1.0$ $\mathrm{MPa}$. Steps give the squeezing pressure upon an exemplar of sand. In this research the squeezing pressure changes from 0.017 MPA to 0.17 MPA.

\section{Experiment}

The first series of an experiment was carried out on fine sand and medium sand in low-wet sand and water-saturated sand. Schedules of dependence of the relative deformations of above-mentioned soils are present in Figures with 1 to 4 . As deformations of an exemplar of sand mean values according to indications of devices undertook.

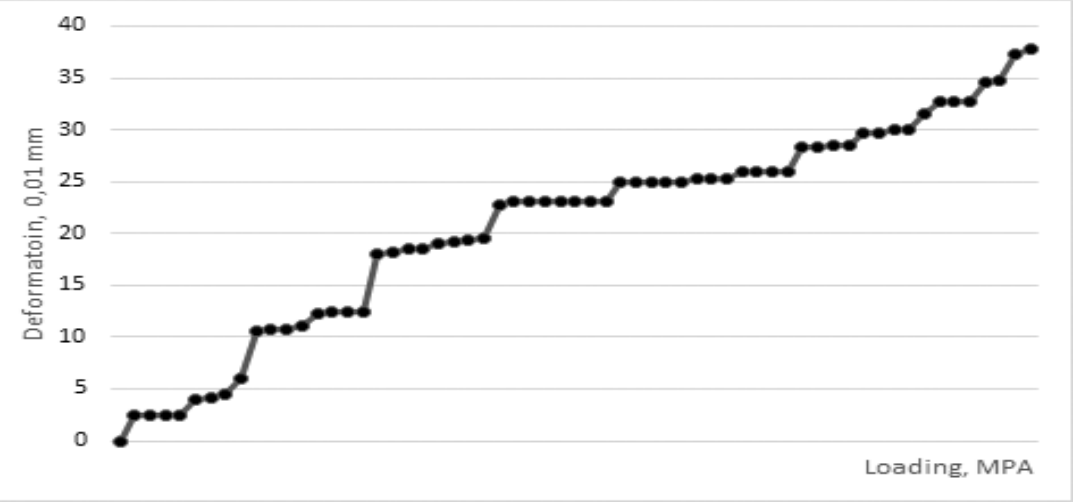

Fig. 1. Schedule of deformation of low-wet fine sand 


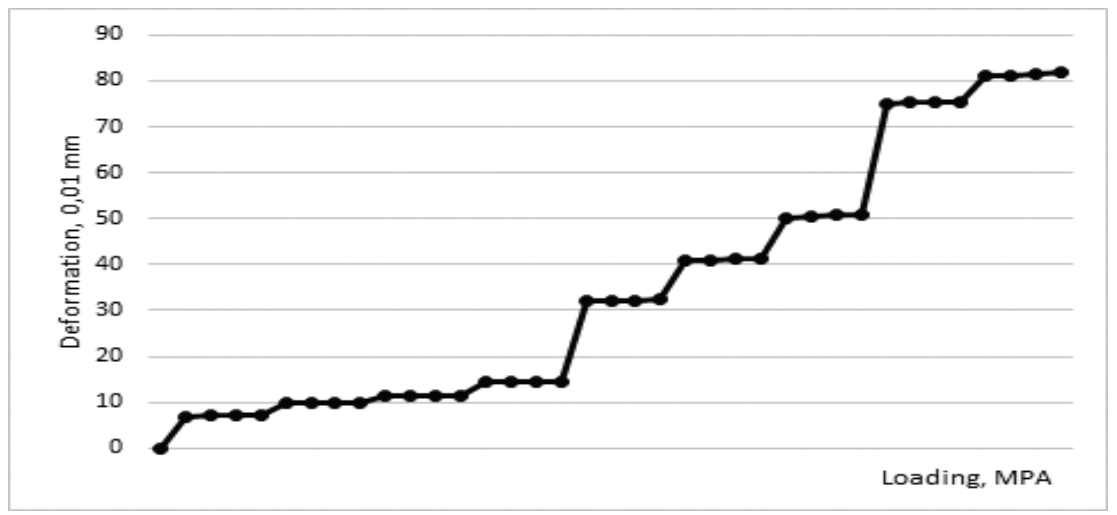

Fig. 2. Schedule of deformation of low-wet medium sand

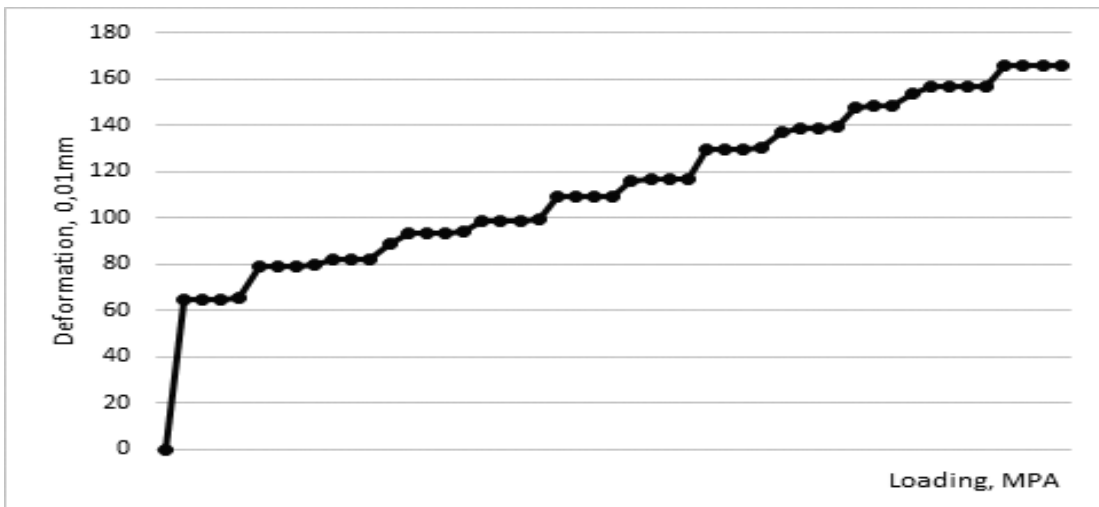

Fig. 3. Schedule of deformation of water-saturated fine sand

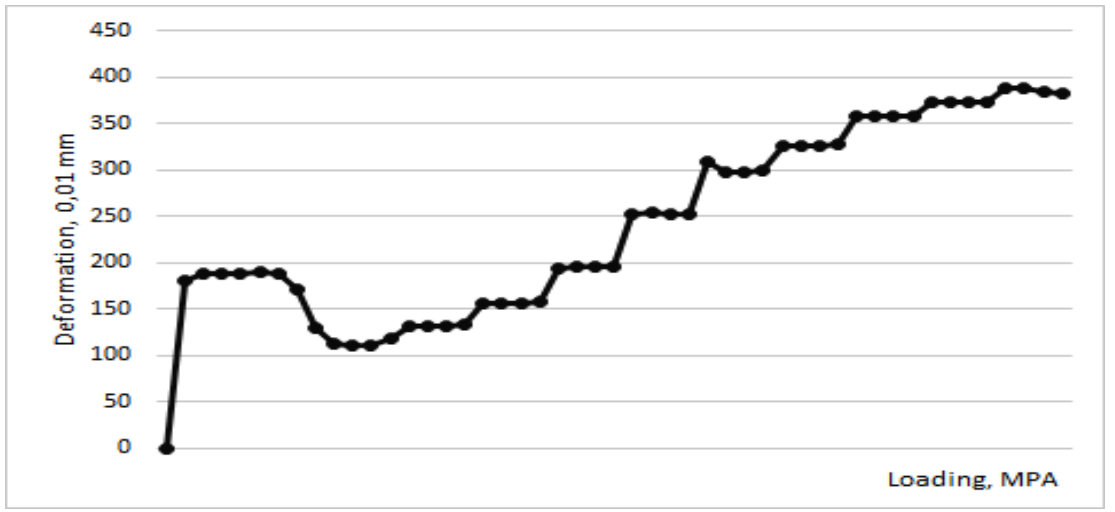

Fig. 4. Schedule of deformation of water-saturated medium sand

The second series of an experiment a low-wet fine sand, a low-wet medium sand, watersaturated fine sand and water-saturated medium sand polluted by benzine (gasoline). Benzine (gasoline) was added to the studied sand exemplar before the maximal absorption of gasoline.

Schedules of dependence of the relative deformations of above-mentioned soils are present in Figures with 5 to 8. 


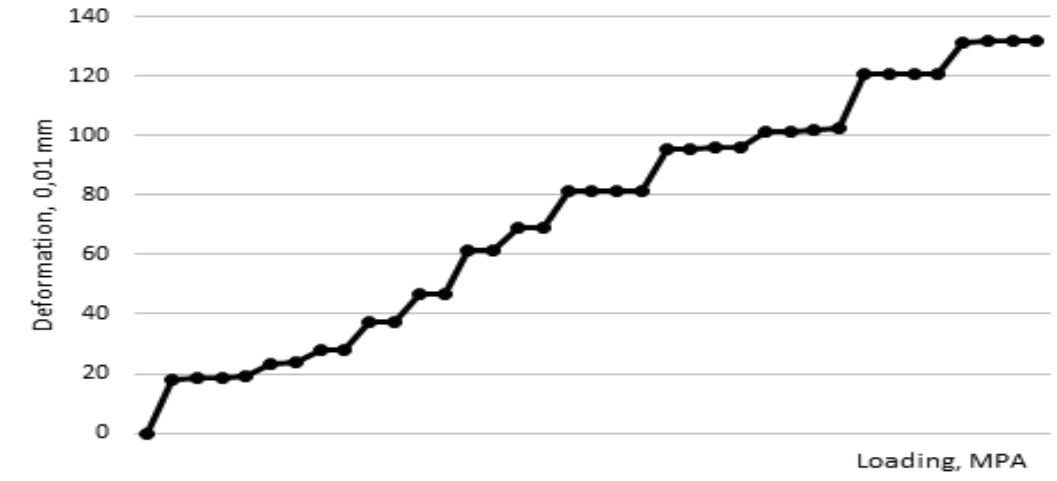

Fig. 5. Schedule of deformation of low-wet fine sand with benzine (gasoline)

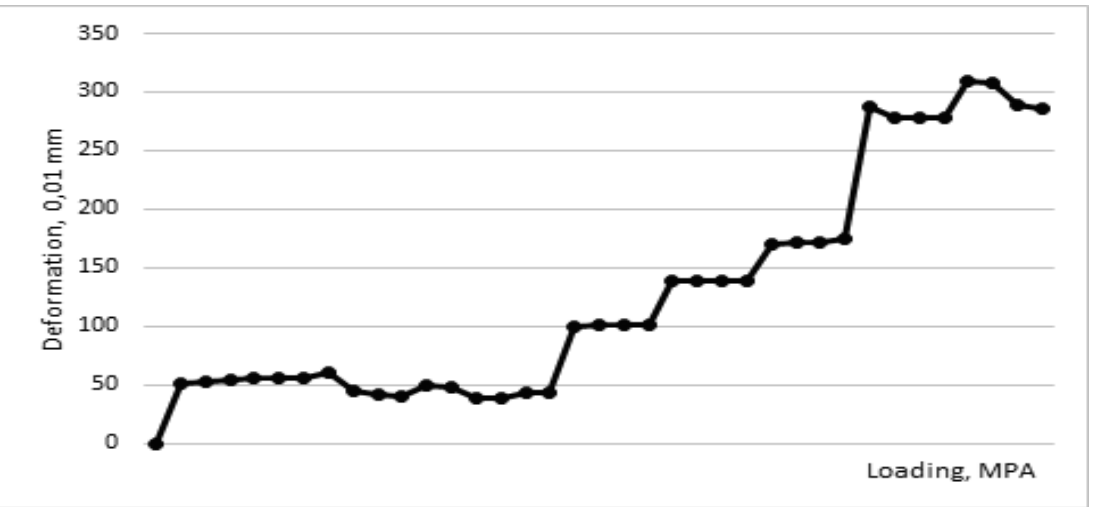

Fig. 6. Schedule of deformation of low-wet medium sand with benzine (gasoline)

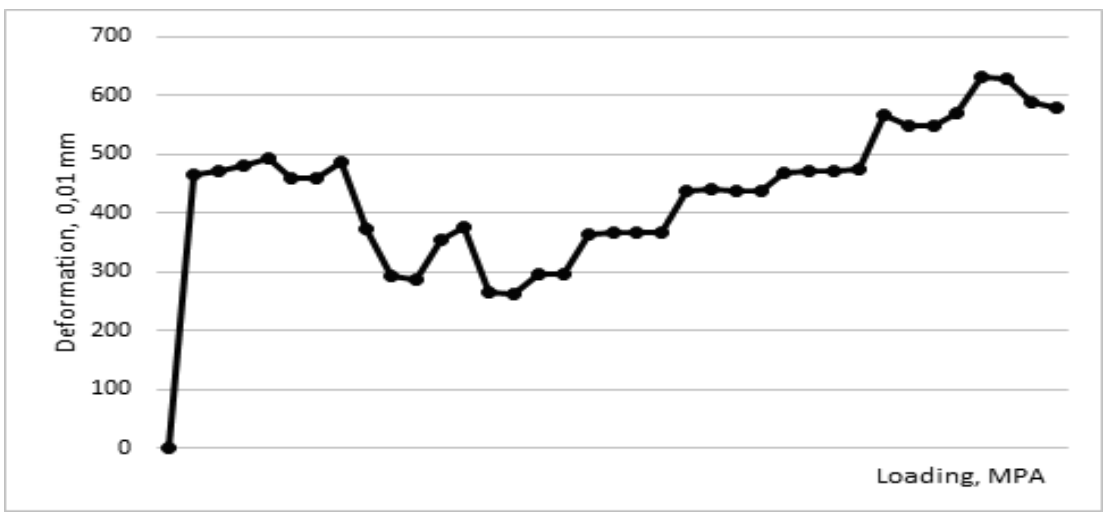

Fig. 7. Schedule of deformation of water-saturated fine sand with benzine (gasoline) 


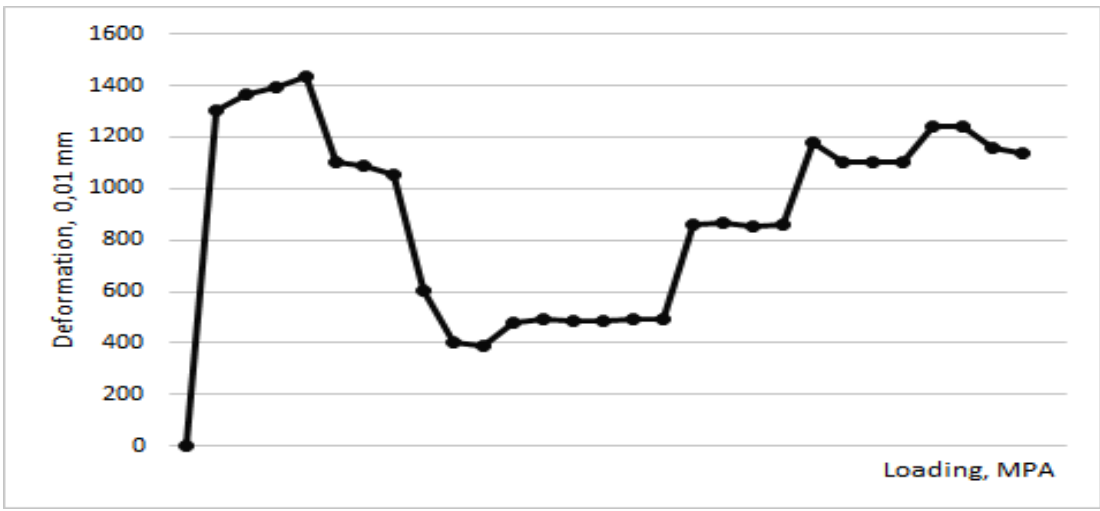

Fig. 8. Schedule of deformation of water-saturated medium sand with benzine (gasoline)

Third series of an experiment a low-wet fine sand, a low-wet medium sand, watersaturated fine sand and water-saturated medium sand polluted by diesel. Diesel was added to the studied sand exemplar before the maximal absorption of fuel.

Schedules of dependence of the relative deformations of above-mentioned soils are present in Figures with 9 to 12.

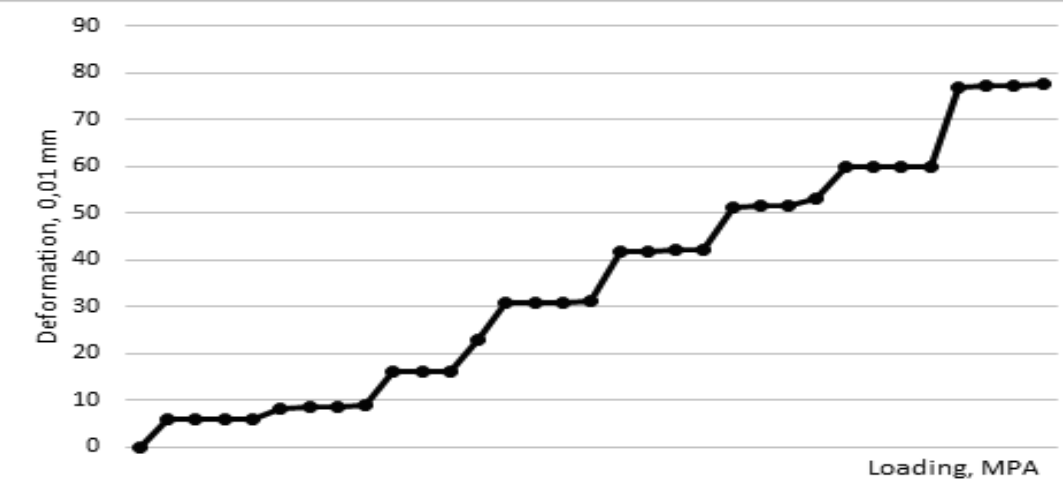

Fig. 9. Schedule of deformation of low-wet fine sand with diesel

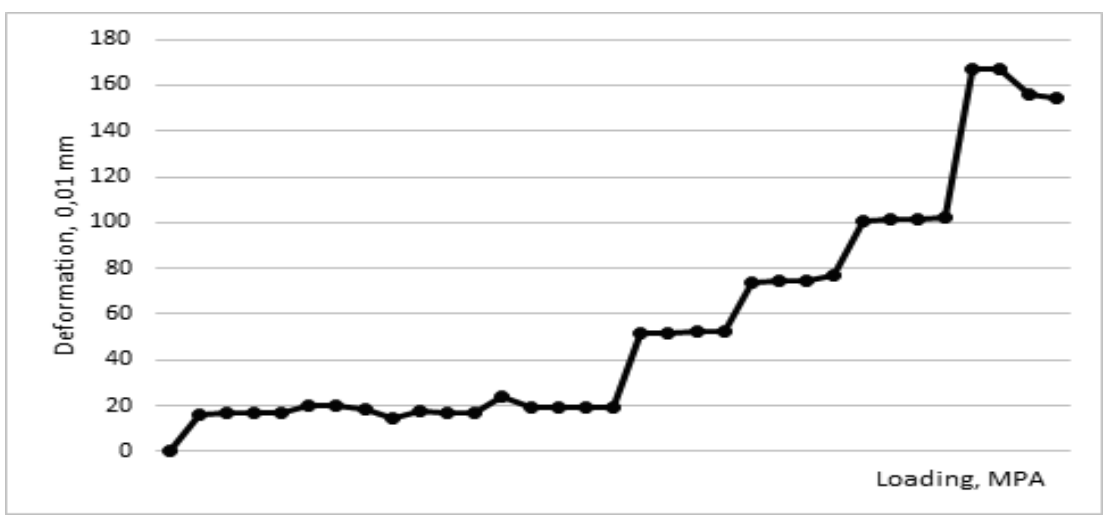

Fig. 10. Schedule of deformation of low-wet medium sand with diesel 


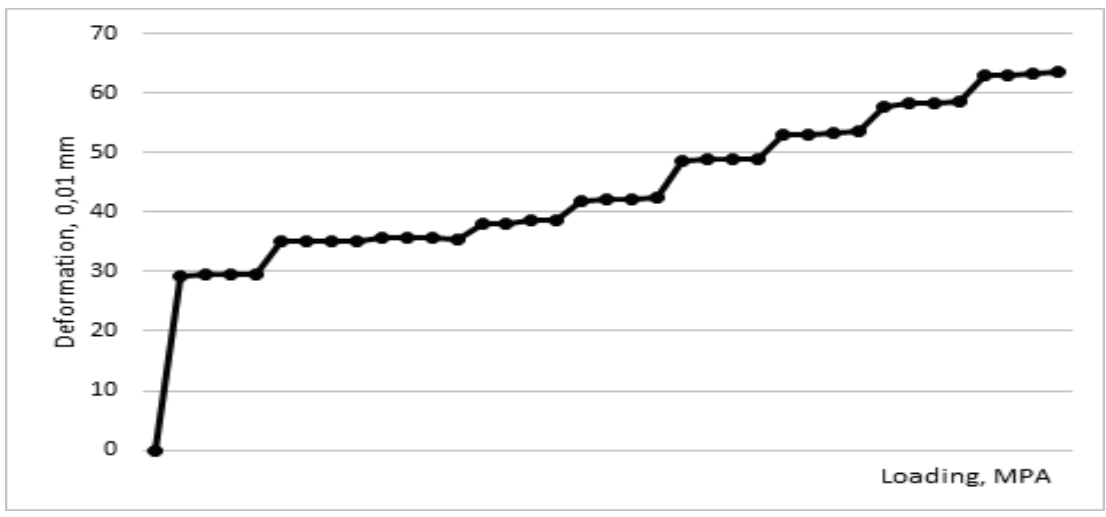

Fig. 11. Schedule of deformation of water-saturated fine sand with diesel

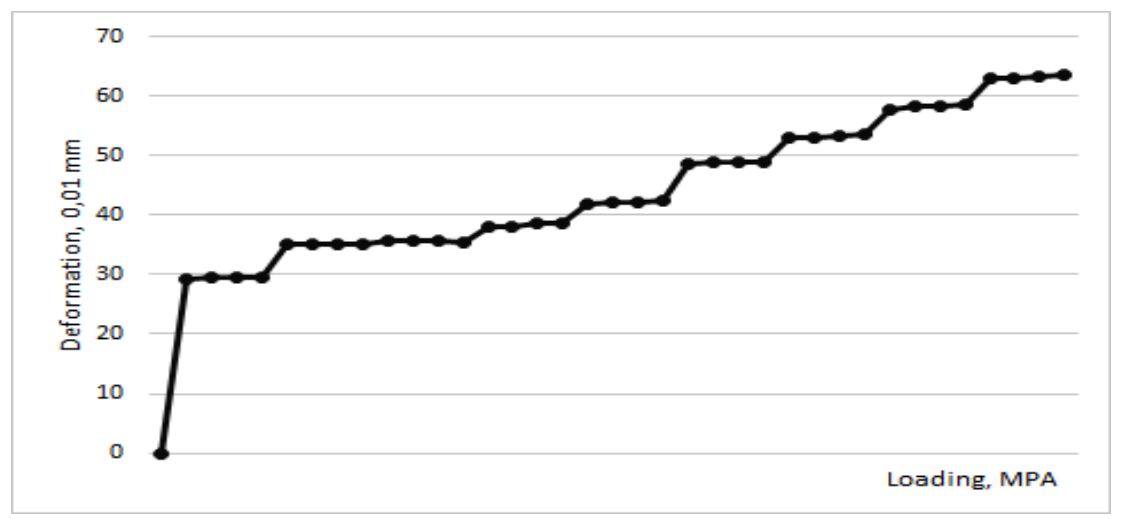

Fig. 12. Schedule of deformation of water-saturated medium sand with diesel

\section{Conclusions}

The first series of an experiment was made to have results with which it is possible to compare results of an experiment to the sand polluted by oil products.

In the analysis of the first series of experiments, it is possible to draw a conclusion that the low-wet fine sand has smaller compressibility, than the low-wet medium sand. In addition, water-saturated medium sand has the larger compressibility. The received result is explained by the fact that the porosity of the sandy massif is less at denser adhering of shallow particles to each other. At the same time availability of water between particles does not promote such adhering. The first series of an experiment can be considered reference for further comparison with the received results of the polluted sands.

When comparing fine low-wet sand (Figure 1) and the same sand with gasoline (Figure $5)$ it is visible that the character of a curve compression remained almost the same. However, at the same time, it is absolutely expected, compression of an exemplar of sand increased. It is bound to the fact that gasoline, as well as water in water-saturated sand, filled all space between particles of fine sand. The same happens to the low-wet medium sand (Figure 2) and the sand (Figure 6) polluted by benzine (gasoline).

At pollution of water-saturated sand other picture occurs gasoline. At pollution of water-saturated fine sand (Figure 3, Figure 7) at initial small loadings water replacement with gasoline happened benzine (gasoline). At increase in loading, there is a so-called rise of a soil when the soil seeks to return to tentative volume. At this time at sand density 
decreased. It is visible from schedules since deformation of sand with benzine (gasoline) increases. At the same time benzine (gasoline) and water approximately in equal quantity were squeezed out on an exemplar surface in the odometer. At further increase in loading water started over again filtering into an exemplar and to fill the grains a sandy exemplar. Gasoline as lighter liquid remained on a surface also it was absorbed to the high layer.

Average water-saturated sand (Figure 4) polluted by gasoline (Figure 8) also has a sand exemplar rise with gasoline, but at the same time average sand more long time is not deformed from the increasing loading. It is also possible to see that irrespective of fineness of sand its rise and a loosening in size will be identical.

From all this it is possible to draw a conclusion that at any humidity of sand at pollution loosening of the ground massif and decrease to resistance of deformations happens its gasoline. This conclusion is important for operation of the excavator on excavation of sand from a ditch. At excavation of the sands polluted by gasoline it is possible to use easier (that is cheap) the excavator.

When comparing the low-wet sands polluted by solar oil (Figure 9-10) with uncontaminated low-wet sands (Figure 1-2) it is visible that the compression curve of schedules on an outline repeats schedules at pollution of such sands benzine (gasoline). Only the different size of deformation. At pollution of the low-wet sands, the diesel deformation is less, than at pollution by benzine (gasoline), but it is more, than at clean sand.

If to compare the water-saturated sand polluted by the diesel (Figure 11-12) with clean sand, then it is visible that sand with the diesel has the smaller size of deformation, than sand without diesel. In other words, the diesel condenses sand. At the same time when carrying out these experiments water from sand was squeezed out on the surface of the odometer. Also from schedules, it is visible that fineness of sand does not influence straining characteristics of the sand polluted by the diesel.

Why? I have no answer. Maybe it happens because of paraffin, which is a part of the diesel? To answer these questions the detailed research of influence of solar oil on watersaturated sands is necessary. This research is necessary in order that further substances from the diesel, which raise straining characteristics of water-saturated sands, could be used for increase in a carrying capacity of soils.

\section{References}

1. Interstate Standard GOST 8736-93. Sand for construction works. Technical specifications (1995)

2. ISO 14688-2:2004 Geotechnical investigation and testing - Identification and classification of soil - Part 2: Classification principles and quantification of descriptive characteristics (2004)

3. National Standard GOST 54283-2010. Motor fuels. Uniform designation of automobile gasolines and diesel fuels being in circulation on the territory of the Russian Federation (2011)

4. Interstate Standard GOST 305-82. Diesel fuel. Specifications (1983)

5. ASTM D 2487-2000. Standard Test. Method for Classification of Soils for Engineering Purposes (2000)

6. Interstate Standard GOST 25100-2011. Soils. Classification (2013)

7. Interstate Standard GOST 8735-88. Sand for construction work. Testing methods (1989) 